\title{
GCU
}

Glasgow Caledonian

University

University for the Common Good

\section{DC-DC converter concept allowing line commutated converters and voltage source converters based HVDC systems connectivity}

Elgenedy, Mohamed; Ahmed, Khaled Hani ; Aboushady, Ahmed A. ; Abdelsalam, Ibrahim

Published in:

IET Power Electronics

DOI:

10.1049/iet-pel.2020.0054

Publication date:

2020

Document Version

Author accepted manuscript

Link to publication in ResearchOnline

Citation for published version (Harvard):

Elgenedy, M, Ahmed, KH, Aboushady, AA \& Abdelsalam, I 2020, 'DC-DC converter concept allowing line commutated converters and voltage source converters based HVDC systems connectivity', IET Power Electronics, vol. 13, no. 15, pp. 3294-3304. https://doi.org/10.1049/iet-pel.2020.0054

\section{General rights}

Copyright and moral rights for the publications made accessible in the public portal are retained by the authors and/or other copyright owners and it is a condition of accessing publications that users recognise and abide by the legal requirements associated with these rights.

Take down policy

If you believe that this document breaches copyright please view our takedown policy at https://edshare.gcu.ac.uk/id/eprint/5179 for details of how to contact us. 


\title{
A New DC-DC Converter Concept Allowing Line Commutated Converters and Voltage Source Converters Based HVDC Systems Connectivity
}

\author{
M. A. Elgenedy ${ }^{1,2 *}$, K.H Ahmed ${ }^{1}$, A.A Aboushady ${ }^{3}$, and I. Abdelsalam ${ }^{4}$ \\ ${ }^{1}$ Current affiliation: Electronic and Electrical Engineering, Strathclyde University, Glasgow G1 1RD, UK \\ ${ }^{2}$ Electrical Power Engineering, Alexandria University, Alexandria, Egypt \\ ${ }^{3}$ School of Engineering and Built Environment, Glasgow Caledonian University, 70 Cowcaddens Road, \\ Glasgow, UK \\ ${ }^{4}$ Electrical and Control Department, College of Engineering and Technology, Arab Academy for Science, \\ Technology and Maritime Transport, Cairo, Egypt \\ *corresponding author: mohamed.elgenedy@strath.ac.uk
}

\begin{abstract}
The common two challenges in high voltage dc (HVDC) multi-terminal transmission are the dc fault isolation and the dc voltage stepping up/down. Additionally, interconnecting voltage source converter (VSC) and line commutated converters (LCC) based HVDC network topologies has been challenging. This paper, introduces a new dc-dc converter topology concept connecting both LCC and VSC based HVDC networks with bidirectional power flow without operation stoppage. The proposed topology is formed of two front-to-front connected bridges with an ac-link formed of a capacitor and an inductor (which can be replaced by a transformer for voltage step up/down). The LCC-HVDC network bridge is formed of insulated gate commutated thyristors while the VSC-HVDC network bridge is formed of insulated gate bipolar transistors. Therefore, ON/OFF switching of both bridges and bi-directional power flow are possible. Moreover, the reactive power transfer is nullified at rated active power exchange between the proposed converter bridges. The proposed concept detailed analysis and control equations are introduced. Different operation scenarios are simulated. In addition to a scaled-down experimentation to test the applicability of power transfer scenarios without operation stoppage in normal operation.
\end{abstract}

\section{Introduction}

High voltage direct current (HVDC) transmission networks based on voltage source converter (VSC) have been investigated massively [1]-[3], especially after the proposed modular multi-level converter (MMC) concept by Marquardt [4]. Nevertheless, the majority of the existing HVDC transmission networks are based on line commutated converter (LCC) using thyristor valves, which are current source converters (CSC) in nature [5]. Each technology has its pros and cons, for example, reaching the operation efficiency level for VSCs as in LCC HVDC networks is still challenging [6]. In contrast, independent active and reactive power control as well as power reversal is easier in VSCs, let alone the absence of the commutation failure [2]. In addition, the footprint of the LCC based converter station is larger compared to VSC converter station due to the large reactive power capacitor banks [6].

Having a robust multi-terminal HVDC network is being hindered by two main challenges namely: the ability of dc fault isolation and connection possibility of different $\mathrm{dc}$ voltage level HVDC networks [7]. One of the key solutions to these challenges is the dual active bridge (DAB) converters [8]. A DAB dc-dc converter has two conversion stages, where both involved dc-voltage levels are converted into ac voltages via dc-ac bridges. The dc-ac bridges are connected front-tofront $(\mathrm{F} 2 \mathrm{~F})$ as in Fig. 1 through an $n$-turns ratio transformer connecting two HVDC network terminals to match different dc voltage levels. The F2F bridges ac waveforms are phaseshifted to allow power transfer between the HVDC networks. Several DAB dc-dc topologies have been proposed in literature for either connecting VSC-HVDC networks; or LCC-HVDC networks [9]-[16].

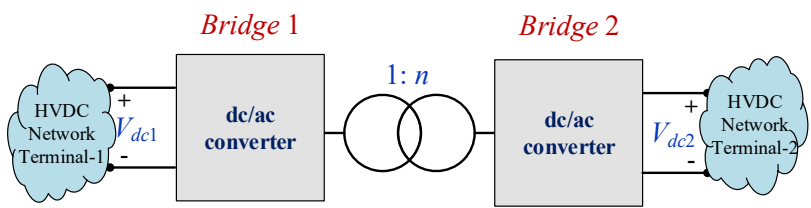

Fig. 1. Conceptual DAB converter.

Generally, dc-dc converters can be divided into three main groups as follows [17]-[19]:

- $\quad$ Single-stage dc-dc converter. In this category, the same current flows between input and output. These topologies are widely used for switched mode power supplies (SMPS) and can be isolated or non-isolated. Moreover, they can step the dc voltages up or down. Examples for this category are buck, boost, buck-boost and flyback converters. Nevertheless, the power ratings for such converters typically is $5 \mathrm{~kW}$ and cannot be used for HVDC systems.

- Bridge based dc-dc converters. In this category, a bridge is dedicated for each dc side. The bridges convert the $\mathrm{dc}$ voltage into ac. They are connected together via an internal circuitry. Normally, this circuit has a transformer like DAB in Fig. 1 hence, both systems are isolated and the stepping ratio $n$ is provided. However, non-isolated systems are also available and the internal circuitry (formed of energy storing passive elements such as inductors, capacitors or combination of both) can help in stepping the dc voltage up or down. The isolated or non-isolated bridge based systems can be utilised in HVDC applications. The major challenges for non-isolated systems are realizing the high voltage isolation for the driver circuits, series connection of semiconductor devices. In contrast, the challenges in isolated systems are transformer design and high 
switching frequency operation in order to increase the system power density with maximized efficiency.

- Series connected converter modules. Several converter modules can be utilised in order to overcome their limited power capability, example of this is the inputparallel/output-series dc-dc converters, which allow stepping the output voltage to higher levels. However, in such case a proper control philosophy should be adopted to assure stable operation of the modules and avoid overloading.

It is believed that migrating the HVDC networks from LCC based to VSC based will not be as fast as the research pace [5]. Hence, LCC-HVDC networks must be incorporated not only in point to point connections but in multi-terminal HVDC grid vision as well. A few studies have explored a solution in which an LCC connected to a VSC through dc cable [20]. These solutions mainly focus on unidirectional power flow control perspective. Since the power reversal cannot be carried out without stopping the operation. This is because in the LCC the dc voltage reversal is required while maintaining the dc current unchanged in VSC the case is reversed. Other F2F topologies [21]-[23] provided generic connectivity solutions with ability to connect hybrid as well as non-hybrid HVDC systems. However, two major common drawbacks are evident: the complexity of control and the huge number of incorporated component.

Generally, the key challenges for adopting VSC based dcdc converters solutions for LCC-HVDC networks are the need of reverse voltage blocking and self-commutation capabilities. Recent research in insulated gate commutated thyristor (IGCT) prove its potential in HVDC applications [24]-[25]. Additionally, with its reverse blocking capability, high power ratings and self-commutation features it can be utilised for LCC-HVDC and VSC-HVDC network integration.

The main contribution of this paper is proposing a new dcdc converter concept, which allow connecting both the LCCHVDC and the VSC-HVDC networks without operation stoppage. The proposed topology advantages can be summarised as follows:

- Enabling the interconnection between the existing LCCHVDC and the newly emerged VSC-HVDC networks.

- Integration of transformer, which not only allow fault isolation but also provide high stepping ratio with prefect switch utilisation.

- Bi-directional power flow is assured with reduced number of components and without utilising complicated control or system shutdown.

- The increased degree of freedom from the added $L C$ components is used to nullify the reactive power at rated active power transfer.

This paper is organised as follows. Section 2 introduces the proposed dc-dc converter with the related principle of operation and comprehensive design equations. Sections 3 and 4 show the simulations and the experimental validation of the proposed converter power transfer capabilities. Finally, section 6 explores the proposed topology variation and challenges.

\section{DC-DC Converter Topology Description}

The dc-dc converter topology is depicted in Fig. 2a in its single-phase form. It can be extended to three-phase as shown in Fig. 2b. In order to introduce the proposed concept for LCC-HVDC and VSC-HVDC connectivity two simplifications are made without loss of generality. First, the single-phase version will be discussed and fully analysed. Second, two-level converters with series connection switches are used. Hence, a dedicated focus will be given for the concept validation without diverting the readers to topological details.

As shown in Fig. 1a, the proposed converter is formed of two bridges, Bridge-I (B-I) and Bridge-II (B-II). B-I is a CSC fed from an LCC-HVDC system. In contrast, B-II is a VSC fed from a VSC-HVDC system. Therefore, the dc link inputs $I_{d c 1}$ and $V_{d c 2}$ for B-I and B-II, respectively, have fixed polarity. B-I is formed of insulated gate commutated thyristor (IGCT) switches $T_{i}$ (where $i \in\{1,2,3,4\}$ ) with reverse blocking capability. The bidirectional current capability is required in B-II. Hence, B-II is formed of insulated gate bipolar transistor (IGBT) switches $S_{i}$ along with anti-parallel diodes $D_{i}$. Both bridges are F2F connected via an ac link formed of capacitor $C$ and a transformer of leakage inductance $L$ and turns ratio $n$. The proposed converter not only allow connection between LCC and VSC based HVDC systems, but also it has a fault proof from the LCC side. Hence, a dc fault is blocked when occurred at the LCC dc link. The VSC bridge is defenceless against dc side faults, nevertheless, during dc pole to pole the faults on B-II, the LCC Bridge will be isolated. Therefore, the fault will not propagate.
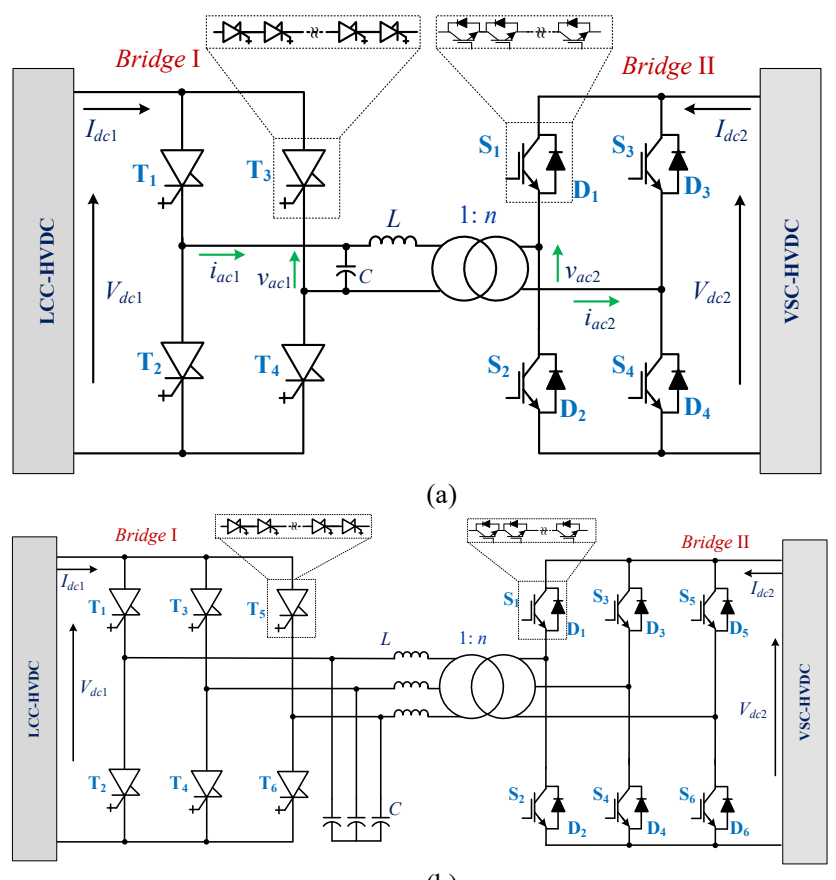

(b)

Fig. 2. Proposed converter circuit (a) Single-phase topology (b) Three-phase topology.

\subsection{Converter Analysis}

In order to allow power transfer between both bridges, the dc link voltage $V_{d c 1}$ and current $I_{d c 2}$ for B-I and B-II, respectively should be able to reverse their polarity. This can be done by proper switching of the bridges switches $T_{i}$ and $S_{i}$. Generally, an ac current $i_{a c 1}$ and an ac voltage $v_{a c 2}$ are 
generated by applying a $50 \%$ duty cycle gate signals to the bridge switches such that the switches in each leg are operated in complementary mode. By introducing a phase shift between the B-I generated ac current and B-II generated ac voltage, the power can be exchanged between them. Fig. 3 shows the modulation principle of the two bridges when B-II ac voltage, $v_{a c 2}$, is shifted by angle $\delta$ from B-I ac current, $i_{a c 1}$.

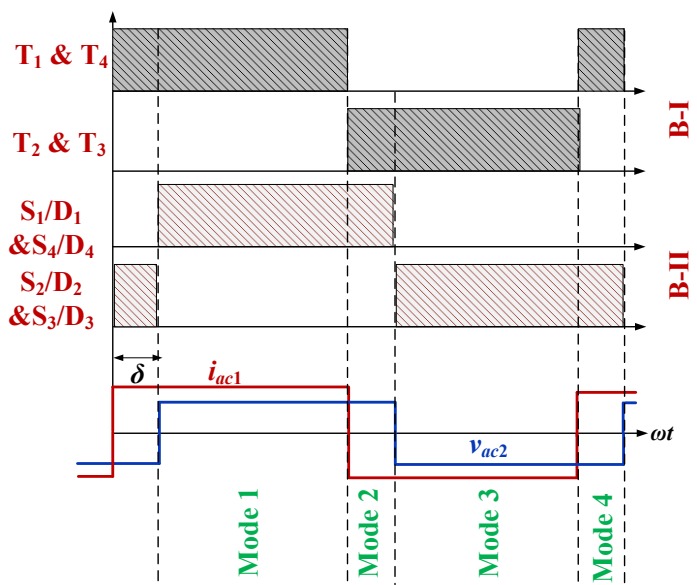

Fig. 3. Modulation principle for B-I and B-II during the four operation modes.

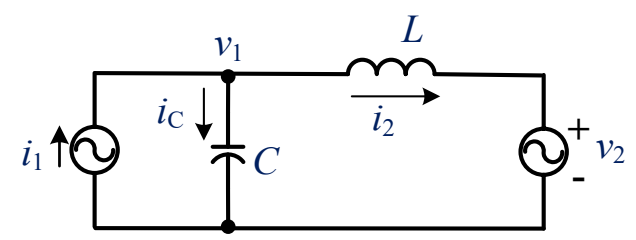

Fig. 4. Simplified converter circuit.

The simplified converter circuit is depicted in Fig. 4. Without loss of generality, only the fundamental component of the square current $i_{a c 1}$ and voltage $v_{a c 2}$ waveforms, shown in Fig. 3, will be considered. B-I ac current fundamental component is denoted $i_{1}(t)$ and its waveform will be the reference. Similarly, B-II ac voltage fundamental component is denoted $v_{2}(t)$ and it lags $i_{1}(t)$ by an angle $\delta$. Hence, $\delta$ is the phase shift angle between B-I and B-II. In order to simplify the circuit analysis, the single phase shift approach is adopted and all the circuit variables will be represented in phasor form as follows

$$
\begin{gathered}
\bar{I}_{1}=I_{1} \angle 0=I_{1}+j 0 \\
\bar{V}_{2}=V_{2} \angle-\delta=V_{2} \cos \delta-j V_{2} \sin \delta
\end{gathered}
$$

where $I_{1}$ and $V_{2}$ are the peak value of the fundamental current and voltage ac waveforms, respectively. Based on Fig. 4

$$
\begin{gathered}
\bar{I}_{1}=\bar{I}_{C}+\bar{I}_{2} \\
\bar{I}_{C}=j \omega C \bar{V}_{1} \\
\bar{I}_{2}=\bar{I}_{1}-j \omega C \bar{V}_{1}
\end{gathered}
$$

Hence

$$
\bar{V}_{1}=\frac{\bar{V}_{2}+j \omega L \bar{I}_{1}}{1-\omega^{2} L C}
$$

The apparent power $S_{1}$ for B-I can be calculated as

$$
\begin{gathered}
\bar{S}_{1}=\bar{V}_{1} \bar{I}_{1}^{*} \\
\bar{S}_{1}=\frac{I_{1}}{A}\left(V_{2} I_{1} \cos \delta+j\left(I_{1}^{2} \omega L-I_{1} V_{2} \sin \delta\right)\right)
\end{gathered}
$$

where, $A=1-\omega^{2} L C$.

Assuming B-I and B-II are generating full square wave from dc side current and voltage, respectively, hence

$$
\begin{gathered}
I_{1}=\frac{2 \sqrt{2}}{\pi} I_{d c 1} \\
V_{2}=\frac{2 \sqrt{2}}{\pi} V_{d c 2}
\end{gathered}
$$

Substituting (9) and (10) into (8) while decomposing the real and imaginary parts of $\bar{S}_{1}$ results in obtaining the real power $P_{1}$ and the reactive power $Q_{1}$ supplied by B-I as follows:

$$
\begin{gathered}
P_{1}=\frac{8 I_{d c 1} V_{d c 2} \cos \delta}{\pi^{2}\left(1-\omega^{2} L C\right)} \\
Q_{1}=\frac{8\left(\omega L I_{d c 1}^{2}-I_{d c 1} V_{d c 2} \sin \delta\right)}{\pi^{2}\left(1-\omega^{2} L C\right)}
\end{gathered}
$$

The bridges are assumed to be lossless in addition to neglecting the losses in the transformer and the $L C$ elements. As a result the bridges power are equal and represent the amount of power exchanged between the two dc terminals

$$
P_{d c 1}=P_{1}=P_{2}=P_{d c 2}
$$

Thus, analysing the apparent power at B-II is required to estimate its local reactive power $Q_{2}$ as follows:

$$
\bar{S}_{2}=\bar{V}_{2} \bar{I}_{2}^{*}
$$

From (5) and (6) $\bar{I}_{2}$ can be expressed as

$$
\bar{I}_{2}=\bar{I}_{1}-\frac{1}{A}\left(j \omega C \bar{V}_{2}-\omega^{2} L C \bar{I}_{1}\right)
$$

Substituting (1) and (2) into (15) yield

$$
\begin{aligned}
\bar{I}_{2} & =\left(1+\frac{\omega^{2} L C}{A}\right) I_{1} \\
& -\frac{1}{A} \omega C V_{2} \sin \delta-j \frac{\omega C}{A} V_{2} \cos \delta
\end{aligned}
$$

Considering the imaginary part of (14) after substituting for $\bar{I}_{2}^{*}$ using (16) results in $Q_{2}$ expression

$$
Q_{2}=\frac{1}{A}\left(\omega C V_{2}^{2}-I_{1} V_{2} \sin \delta\right)
$$

Similar to $Q_{1}, Q_{2}$ expression in terms of the $I_{d c 1}$ and $V_{d c 2}$ is given by (18).

$$
Q_{2}=\frac{8\left(\omega C V_{d c 2}^{2}-I_{d c 1} V_{d c 2} \sin \delta\right)}{\pi^{2}\left(1-\omega^{2} L C\right)}
$$

From the power equations, the following remarks can be concluded:

- $\quad$ The active power $P$ transfer between the two bridges can be controlled by one of the three available variables namely: the phase shift angle $\delta$, the switching frequency $\omega$, and the dc input levels.

- As in conventional DAB converters, the simplest control is achieved by controlling the phase shift angle $\delta$.

- The power can be transferred bi-directionally, and the range of operation of $\delta$ for power transfer is shown in Fig. 5. When $0 \leq \delta \leq \frac{\pi}{2}$ the active power is forward transferred from B-I to B-II, while it is reverse transferred from B-II to B-I when $\frac{\pi}{2} \leq \delta \leq \pi$.

- $\quad$ The local reactive powers of both bridges $\left(Q_{1}\right.$ and $\left.Q_{2}\right)$ are dependent on the variation of $\delta$, however, these local reactive powers can be nullified at rated power. This is possible by proper selection of the passive $L$ and $C$ sizes. 


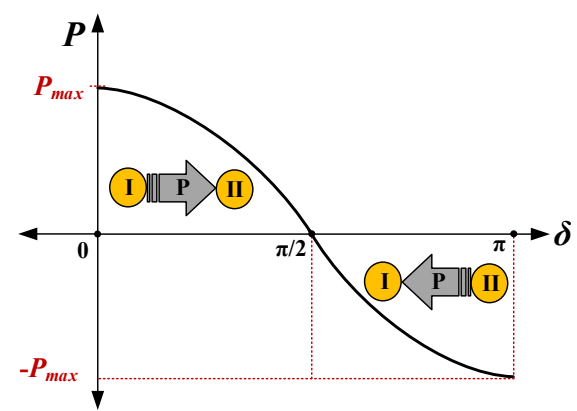

Fig. 5. Variation of phase shift angle and power exchanged between the two bridges.

\subsection{Operation Principal}

The phase shift angle controls the power flow direction, accordingly the LCC and the VSC will adjust the suitable polarity for their $V_{d c 1}$ and $I_{d c 2}$, respectively. Therefore, the corresponding switching pattern must be used to facilitate the

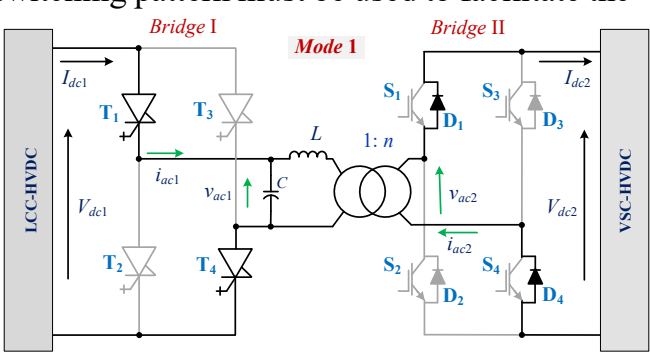

(a)

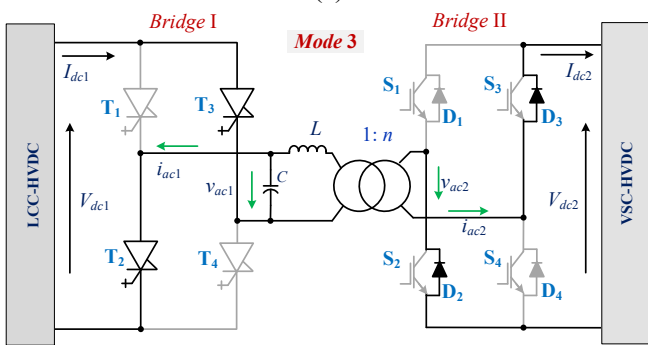

(c) required power follow through B-I and B-II switches. Assuming the current and the voltage polarities shown in Fig. $2 \mathrm{a}$ are positive, there will be 4 modes of operation (see Fig. 3) at forward power as well as at reverse power.

During forward power flow (power from B-I to B-II), the circuit configurations and the active switches are illustrated in Fig. 6. Since $I_{d c 2}$ is negative in B-II, the antiparallel diodes $D_{i}$ operate and the switches $S_{i}$ are switched OFF. In contrast, during reverse power flow (power from B-II to B-I), $I_{d c 2}$ is positive in B-II, therefore, the switches $S_{i}$ operate and the diodes $D_{i}$ are OFF. The circuit configuration and the active switches at reverse power are illustrated in Fig. 7. It is also clear that in both power flow conditions B-I switches $T_{i}$ operated to generate the ac current waveform, since $I_{d c 1}$ has fixed positive polarity. But, the dc voltage $V_{d c 1}$ has negative polarity in reverse power mode, therefore, reverse blocking capability is needed for B-I switches.

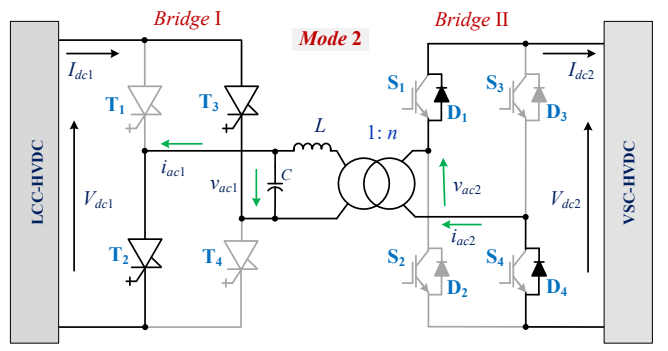

(b)

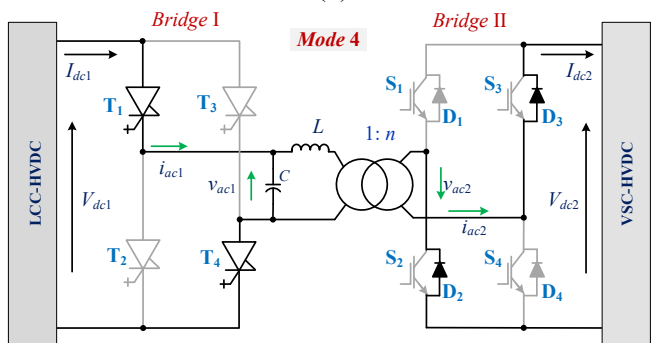

(d)

Fig. 6. Proposed $d c-d c$ converter circuit configuration during forward power flow. (a) Mode 1 . (b) Mode 2. (c) Mode 3. (d) Mode 4.

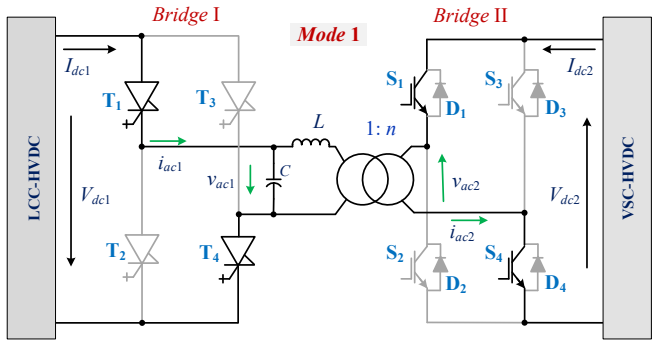

(a)

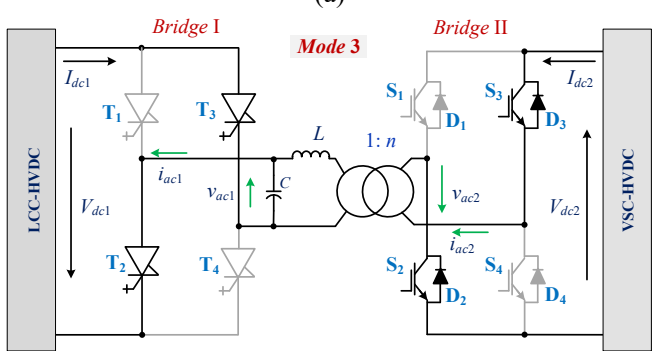

(c)

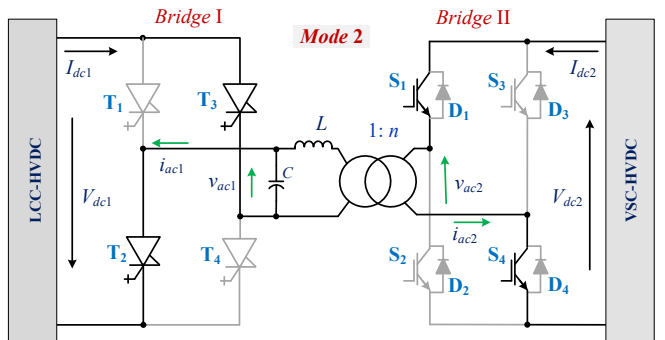

(b)

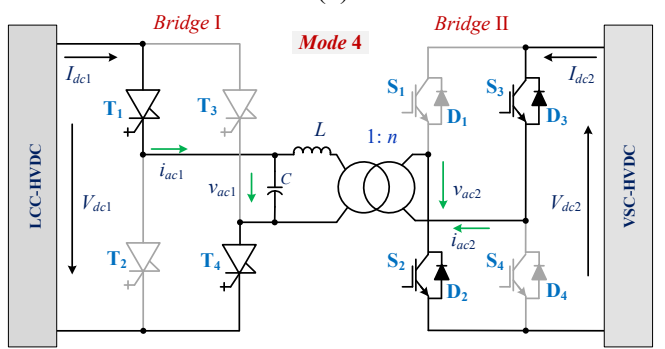

(d)

Fig. 7. Proposed $d c$-dc converter circuit configuration during reverse power flow. (a) Mode 1.

(b) Mode 2. (c) Mode 3. (d) Mode4. 


\subsection{Parameters selection}

As aforementioned, the key factor for the $L C$ selection is to nullify the local reactive powers at the converter rated active power. Normally, nullifying $Q_{1}$ at the rated power will result in the design equation of $L$ while $C$ design equation is obtained from nullifying $Q_{2}$. Hence, the design equations for $L$ and $C$ can be obtained from nullifying (12) and (18), thus

$$
\begin{gathered}
L=\frac{V_{d c 2} \sin \delta}{\omega I_{d c 1}} \\
C=\frac{I_{d c 1} \sin \delta}{\omega V_{d c 2}}
\end{gathered}
$$

It is recommended that the calculated values of $L$ and $C$ are obtained at the rated converter active power. Varying the phase shift angle $\delta$ will directly vary the size of $L C$ elements required to nullify the local reactive powers.

Fig. 8 shows the active and reactive powers exchange with $\delta$ variation, $0 \leq \delta \leq 180^{\circ}$. The rated active power is assumed to be transferred at $\delta=10^{\circ}$. It can be seen that, at $\delta=10^{\circ}$ the reactive powers at B-I and B-II are zero. Additionally, the power is positive at B-I and negative at BII as expected. Varying $\delta$ leads to a corresponding change in the transferred active power according to (11) with non-zero reactive powers according to (12) and (18). Fig. 8 illustrates the potential of the proposed topology to have zero voltage switching (ZVS) and zero current switching (ZCS). If local reactive powers $\left(Q_{1}\right.$ and $\left.Q_{2}\right)$ are nullified at rated power, current will be in phase with voltage, therefore essentially ZVS and ZCS switching both will be achieved. When the power is reduced below the rated power ZVS or ZCS will be achieved depending on the nature of reactive power flow (capacitive or inductive). ZVS is possible with local reactive power at bridge being inductive. ZCS is possible with local reactive power at bridge being capacitive.

Fig. 9 parts a and $\mathrm{b}$ show the per-unit (pu) variation of the $L$ and $C$ with $\delta$, respectively, based on the parameters in Table 1. It can be seen that as $\delta$ increases the $L C$ sizes also increase. Selecting the appropriate $\delta$ for rated power transfer is a tradeoff between the passive component sizes and the required control range. Although the reactive power is not nullified at all loading conditions, this does not necessitate a derating for the bridges switching devices. At the design stage the switches selection should be based on the maximum active and maximum reactive powers that is

$$
\begin{gathered}
P_{\text {max }}=\frac{8 I_{d c 1} V_{d c 2}}{\pi^{2}\left(1-\omega^{2} L C\right)} \\
Q_{\text {max }}=\frac{8\left(\omega L I_{d c 1}^{2}+I_{d c 1} V_{d c 2}\right)}{\pi^{2}\left(1-\omega^{2} L C\right)}
\end{gathered}
$$

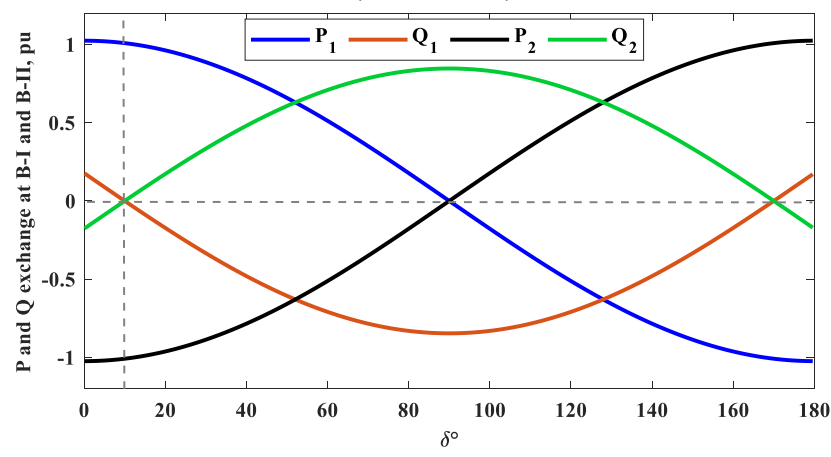

Fig. 8. Per unit variation of active and reactive powers at $B-I$ and $B-I I$ with the phase shift angle $\delta^{\circ}$.

\section{Power Transfer Simulation Results}

The proposed dc-dc converter topology is assessed using MATLAB/Simulink simulations, with the parameters given in Table 1. The ac-link inductance and capacitance are calculated based on (19) and (20), respectively. The obtained inductance value under rated conditions from (19) is $L=$ $92 \mathrm{mH}$. Hence, an inductance of $89.3 \mathrm{mH}$ is added in addition to the ac-link transformer leakage inductance.

Table 1 Simulation Specifications

\begin{tabular}{|l|c|c|}
\hline Rated power (base power) & $P_{r}$ & $410 \mathrm{MW}$ \\
\hline LCC dc current level (base current) & $I_{d c 1}$ & $1000 \mathrm{~A}$ \\
\hline VSC dc Voltage level & $V_{d c 2}$ & $500 \mathrm{kV}$ \\
\hline ac link frequency & $f_{s}$ & $150 \mathrm{~Hz}$ \\
\hline Phase-shift angle at forward rated power & $\delta$ & $10^{\circ}$ \\
\hline \multirow{2}{*}{ ac link transformer } & $\begin{array}{c}\text { Rated } \\
\text { power }\end{array}$ & $500 \mathrm{MVA}$ \\
\cline { 2 - 3 } & $\mathrm{N}_{1} / \mathrm{N}_{2}$ & 1 \\
\cline { 2 - 3 } & $\begin{array}{c}\text { Leakage } \\
\text { impedance }\end{array}$ & $50+\mathrm{j} 2.7 \mathrm{~m} \Omega$ \\
\hline ac link inductance & $L$ & $89.3 \mathrm{mH}$ \\
\hline ac link capacitance & $C$ & $0.37 \mu \mathrm{F}$ \\
\hline
\end{tabular}

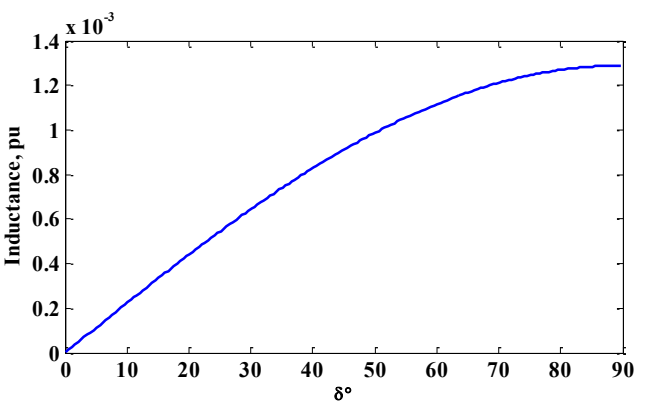

(a)

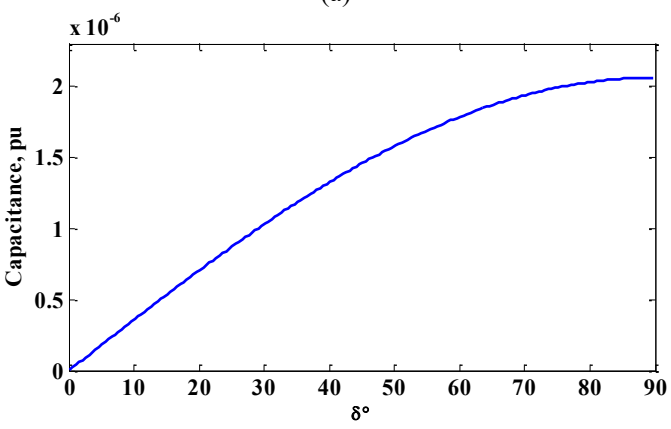

(b)

Fig. 9. Per unit LC size variation with the phase shift angle $\delta^{\circ}$. (a) Inductance. (b) Capacitance.

The pu values are calculated by considering the base power is the rated power and B-I dc current is the base current. Fig. 10 shows the forward (from B-I to B-II) and reverse (from BII to B-I) power transfer at rated as well as partial loading conditions. The power transfer profile is detailed as follows:

- From $t=0$ to $t=0.25 \mathrm{~s}$, converter is operating at full rated power in forward direction.

- From $t=0.25 \mathrm{~s}$ to $t=0.5 \mathrm{~s}$, converter is operating with $0.5 P_{r}$ in in forward direction.

- From $t=0.5 \mathrm{~s}$ to $t=0.75 \mathrm{~s}$, converter is operating with $0.5 P_{r}$ in reverse direction.

- From $t=0.75 \mathrm{~s}$ to $t=1.0 \mathrm{~s}$, converter is operating with full rated power in reverse direction. 
It can be shown in Fig. 10a and Fig. 10b that the active power is transferred, in both directions, with zero local reactive power. As illustrated in Fig. 5, in order to reverse the power from B-II to B-I while keeping the reactive powers nullified; the phase shift angle is increased to $\delta=170^{\circ}$ instead of $\delta=$ $10^{\circ}$ in the forward power transfer case. Moreover, the dc link currents and voltages at bridges terminals are depicted in Fig. 10 parts $\mathrm{c}$ and $\mathrm{d}$ for B-I and B-II, respectively. As expected, $\mathrm{B}-\mathrm{I}$ current is always kept fixed while its dc link voltage is varied. In contrast, the dc link voltage of B-II is fixed while its dc current varied. Transferring the partial power will

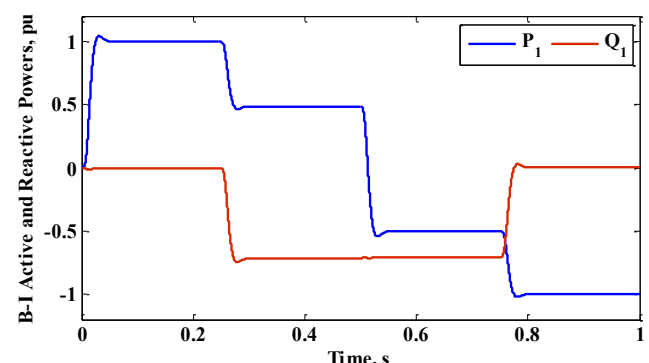

(a)

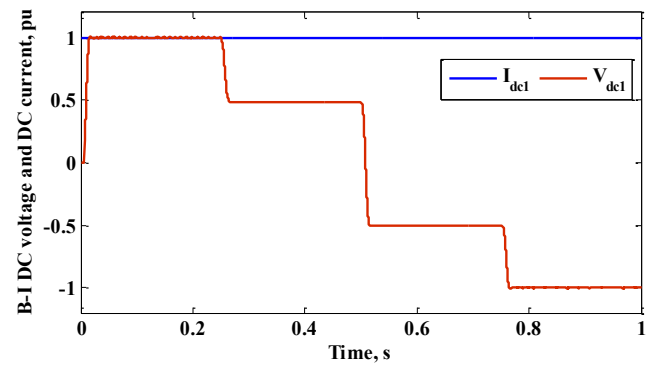

(c) encounter some reactive power transfer as expected. Fig. 11 shows the phase-shift angle variation between the ac link current $i_{a c 1}$ of B-I and the ac voltage $v_{a c 2}$ of B-II. Corresponding to the previously mentioned loading conditions, at forward rated power $\delta=10^{\circ}$ as in Fig. 11a, while at $0.5 P_{r}$ it is increased to $\delta=61.4^{\circ}$ as illustrated in Fig. 11b. Similarly, in reverse power mode $\delta=118.6^{\circ}$ and $\delta=170^{\circ}$ for $P_{r}$ and $0.5 P_{r}$ as shown in Fig. 11c and Fig. 11d, respectively.

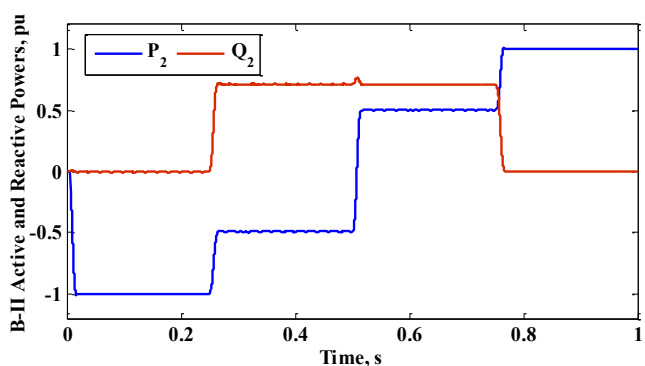

(b)

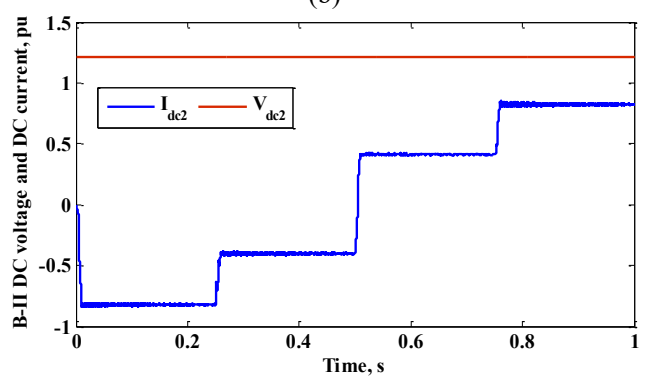

(d)

Fig. 10. Simulation results for power exchange between $B-I$ and $B-I I$. (a) Active and reactive powers at B-I (b) Active and reactive powers at B-II. (c) dc link voltage and current at B-I. (d) dc link voltage and current at B-II.

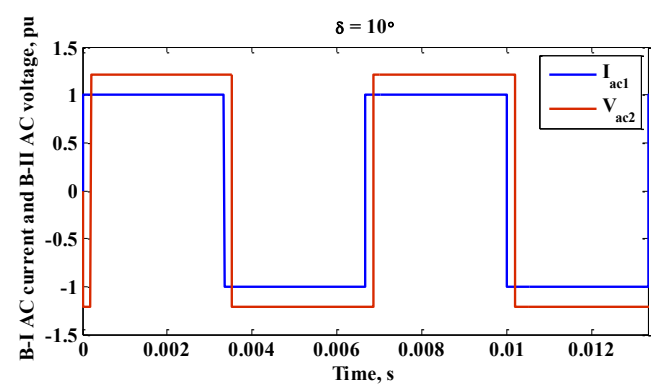

(a)

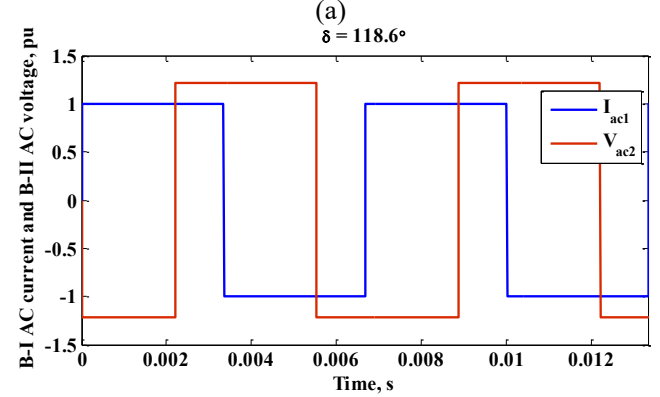

(c)

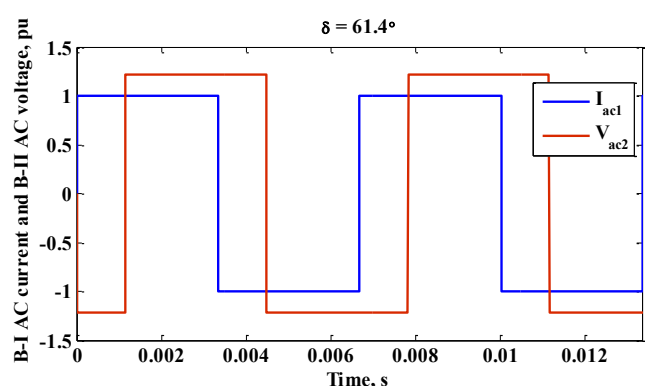

(b)

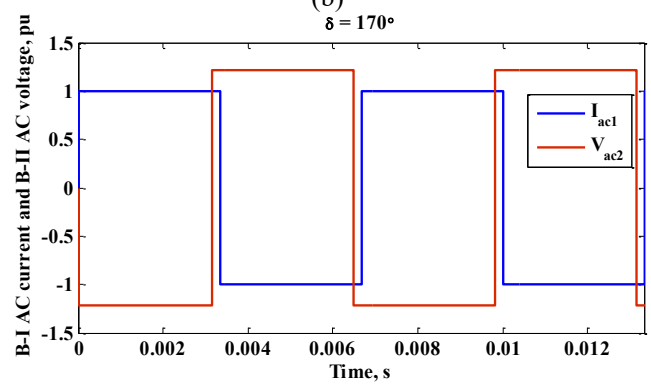

(d)

Fig. 11. Simulation results for phase-shift angle between B-I ac link current and B-II ac link voltage. (a) When forward rated power is transferred (from B-I to B-II). (b) When forward halfrated power is transferred (from $B-I$ to $B$-II). (c) When reverse half-rated power is transferred (from B-II to B-I). (d) When reverse rated power is transferred (from B-II to B-I). 


\section{Power Transfer Experimental Results}

In order to demonstrate the proposed converter practically, a scaled-down experimental set-up is implemented with the specifications listed in Table 2. A stiff LCC is adopted and an ac inductor is used instead of a transformer. The experimental schematic diagram is shown in Fig. 12. Bridge B-I needs reverse-blocking switches; this can be achieved by utilising IGCTs or by using an IGBT in series with a diode. Such approach is widely used in MV drives [26] and wind energy conversion converters [27] and is adopted here instead of the IGCTs for B-I. The VSC side is emulated by a de voltage source feeding B-II (see Fig. 12). The LCC side is emulated by a dedicated circuit and control (see Fig. 12) according to the power flow direction:

- For forward power flow (from B-I to B-II) switches $\mathrm{FB}_{1}$ and $\mathrm{FB}_{4}$ are $\mathrm{ON}$ while $\mathrm{FB}_{2}, \mathrm{FB}_{3}$ and $\mathrm{SW}_{2}$ are OFF. The dclink current is regulated by a PI controller, which generates the duty-cycle of $\mathrm{SW}_{1}$. The switch $\mathrm{SW}_{1}$ operates only in forward power flow.

- For reverse power flow (from B-II to B-I) $\mathrm{FB}_{2}$ and $\mathrm{FB}_{3}$ are $\mathrm{ON}$ while $\mathrm{FB}_{1}, \mathrm{FB}_{4}$ and $\mathrm{SW}_{1}$ are $\mathrm{OFF}$. $\mathrm{SW}_{2}$ duty-cycle will be controlled by the PI controller to keep the converter current constant. The switch $\mathrm{SW}_{2}$ operates only in reverse power flow. In reverse power flow, a power resistor is added in series with $\mathrm{SW}_{2}$ to absorb the power.
Table 2 Experimental Specifications

\begin{tabular}{|c|c|c|}
\hline \multicolumn{3}{|c|}{ Proposed Topology Parameters and Active Components } \\
\hline Rated power (base power) & $P_{r}$ & $400 \mathrm{~W}$ \\
\hline $\begin{array}{l}\text { LCC dc current level (base } \\
\text { current) }\end{array}$ & $I_{d c 1}$ & $60 \mathrm{~A}$ \\
\hline VSC dc Voltage level & $V_{d c 2}$ & $80 \mathrm{~V}$ \\
\hline ac link frequency & $f_{s}$ & $150 \mathrm{~Hz}$ \\
\hline $\begin{array}{l}\text { Phase-shift angle at forward } \\
\text { rated power }\end{array}$ & $\delta$ & $10^{\circ}$ \\
\hline ac link inductance & $L$ & $2.5 \mathrm{mH}$ \\
\hline ac link capacitance & C & $13.8 \mu \mathrm{F}$ \\
\hline $\begin{array}{l}\text { B-II active IGBT switches part } \\
\text { No. }\end{array}$ & $S_{i}$ & IHW30N160R2FKSA1 \\
\hline $\begin{array}{l}\text { B-I active switches part No. } \\
\text { (IGBT in series with Diode) }\end{array}$ & $T_{i}$ & $\begin{array}{c}\text { IHW30N160R2FKSA1 } \\
\text { and } \\
\text { DSEI30-10A }\end{array}$ \\
\hline \multicolumn{3}{|c|}{$\begin{array}{l}\text { Stiff Current Source Generator Parameters and Active } \\
\text { Components }\end{array}$} \\
\hline dc input voltage level & & $150 \mathrm{~V}$ \\
\hline $\begin{array}{l}\text { IGBT switches SW1 and SW2 } \\
\text { part No. }\end{array}$ & & IGW60T120FKSA1 \\
\hline Input power resistor & & $5 \Omega, 750 \mathrm{~W}$ \\
\hline $\begin{array}{l}\text { Voltage reversal bridge IGBT } \\
\text { switches } \mathrm{FB}_{i} \text { part No. }\end{array}$ & & IGW60T120FKSA1 \\
\hline dc-link inductance & & $100 \mathrm{mH}$ \\
\hline
\end{tabular}

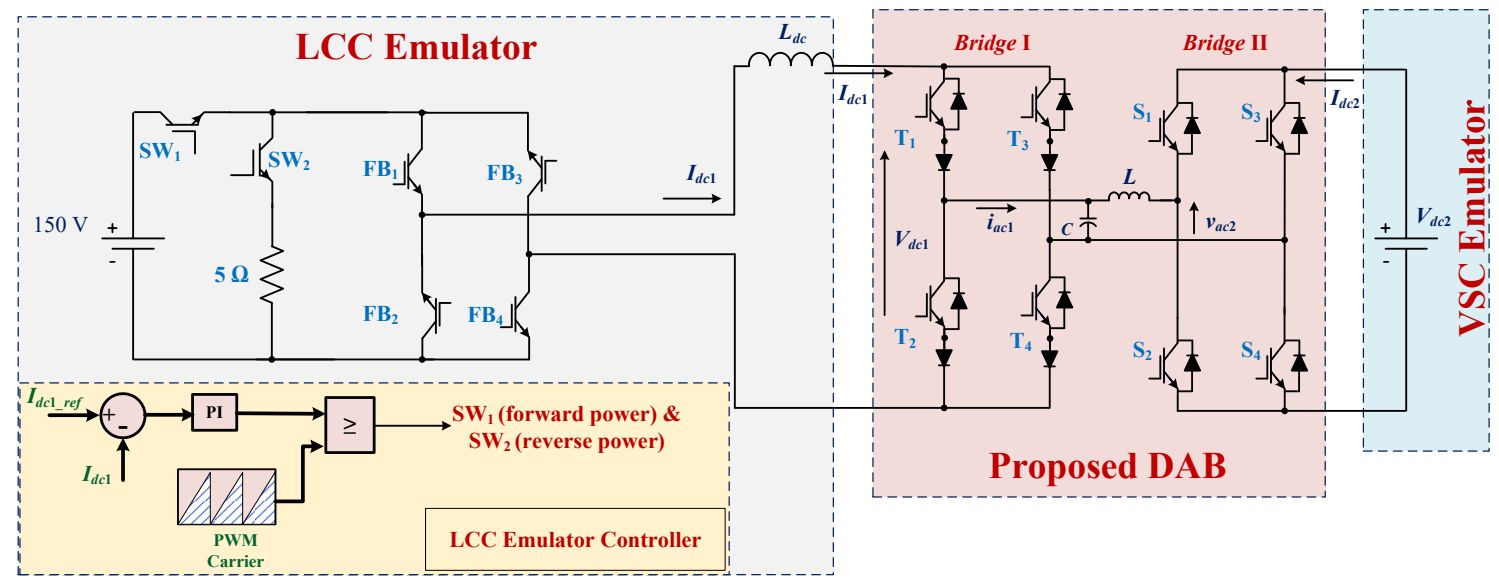

Fig. 12. Schematic diagram for the experimental set-up.

The power transfer profile is detailed in normal operation as follows:

- From $t=0$ to $t=2.5 \mathrm{~s}$, converter is operating at full rated power in forward direction.

- From $t=2.5 \mathrm{~s}$ to $t=5 \mathrm{~s}$, converter is operating with $0.5 P_{r}$ in in forward direction.

- From $t=5 \mathrm{~s}$ to $t=7.5 \mathrm{~s}$, converter is operating with $0.5 P_{r}$ in reverse direction.

- From $t=7.5 \mathrm{~s}$ to $t=10 \mathrm{~s}$, converter is operating with full rated power in reverse direction.

The obtained results are given in Fig. 13. Fig. 13 parts a and b show the dynamic power transfer between B-I and B-II according to the aforementioned power profile in normal operation. It can be seen that, regardless the power direction, BI dc-current is fixed at $6 \mathrm{~A}$ while $\mathrm{B}-\mathrm{II}$ dc voltage is fixed at $80 \mathrm{~V}$ while the dc voltage and the dc current of B-I and B-II respectively are varied to comply with the power transfer amount and direction. For forward power transfer, the phase angle shift between the ac current and the ac voltage of B-I and B-II respectively is $\delta=10^{\circ}$, as shown in Fig. 13c. Also, reverse power transfer is evident at $\delta=170^{\circ}$, as shown in Fig. 13d. Moreover, for $0.5 P_{r}$ transfer in the forward direction the phase shift angle is adjusted at $\delta=60^{\circ}$ as depicted in Fig. 13e. Therefore, by adjusting the phase-shift angle not only the amount of power transfer is controlled, but its direction as well. 


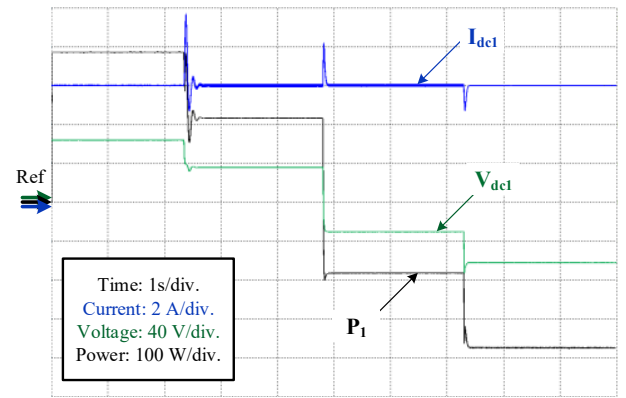

(a)

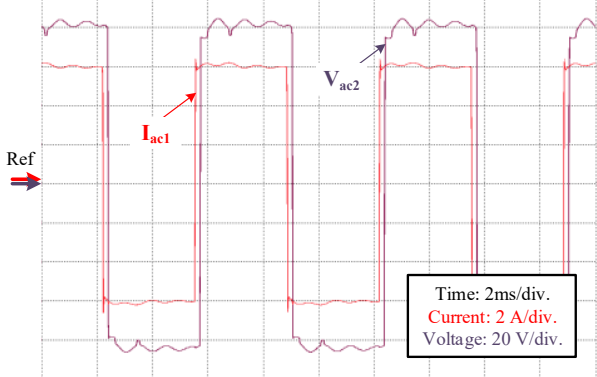

(c)

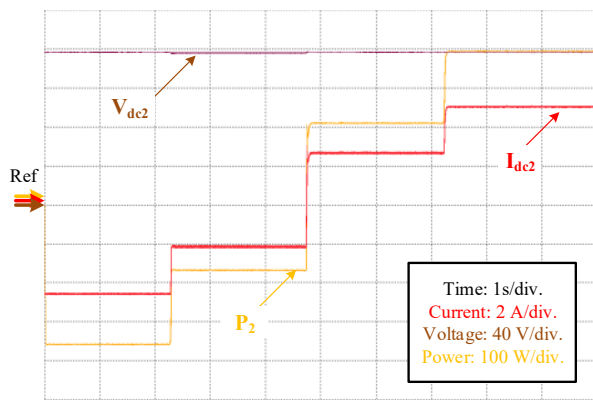

(b)

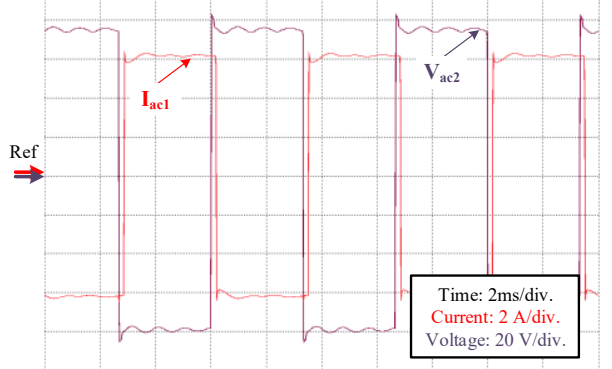

(d)

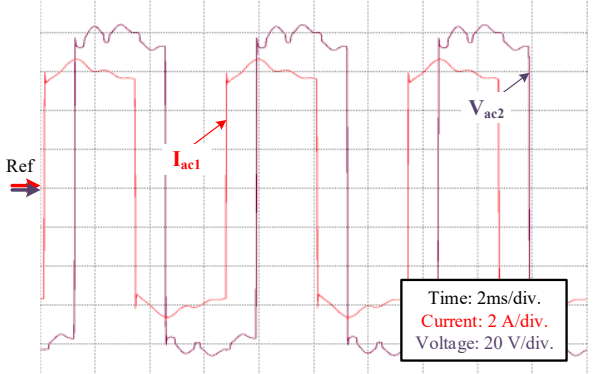

(e)

Fig. 13. Experimental results in normal operation power profile. (a) $B$-I active power, dc link current and dc voltage. (b) B-II active power, dc link current and dc voltage.(c) $B$-I ac current and B-II ac voltage at $\delta=10^{\circ}$. (d) B-I ac current and B-II ac voltage at $\delta=170^{\circ}$. (e) $B$-I ac current and B-II ac voltage at $\delta=60^{\circ}$.

\section{Simulating The Proposed Converter Response During DC-DC Faults}

The response of the proposed converter topology to the dc link pole-to-pole faults is studied without any additional control action or hardware modification. Two scenarios are adopted as illustrated in Fig. 14, when the fault occurs at B-I and B-II dc links when receiving the rated power from the other bridge terminal. In the first scenario, the rated power is transferred to B-I when a dc pole-to-pole fault occurred at the B-I dc-link at $t=0.15 \mathrm{~s}$ as shown in Fig. 15. During the fault, B-I dc link voltage reduced to zero (or closer to zero depending on the fault resistance). Hence the received active power is nullified as shown in Fig. 15 parts a and b. B-I dc link current is fixed at its rated value similar to B-II voltage as shown in Fig. 15 parts $\mathrm{c}$ and d. Additionally, during the fault, some reactive power is evident since the passive elements are feeding the fault. After the fault is cleared at $t=0.25 \mathrm{~s}$, the pre-fault operation is restored and the reactive power is nullified.
Similarly in the second scenario depicted in Fig. 16, a dc pole to pole fault occurred at B-II at $t=0.15 \mathrm{~s}$ when receiving the rated power from B-I. Immediately the dc voltage at B-II is dropped to zero, hence as seen in Fig. 16 parts $\mathrm{a}$ and $\mathrm{b}$ during the fault the active power sent from B-I dropped to zero while the B-II dc current is limited to the rated current, see Fig. 16d. The dc link voltage at B-I is dropped to zero while the dc link current is fixed at its rated value as shown in Fig. 16c.

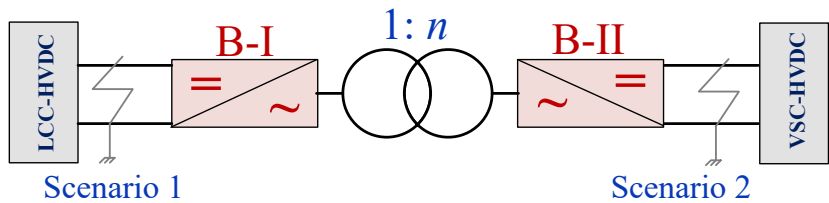

Fig. 14. Applied fault scenarios to study the proposed converter response. 


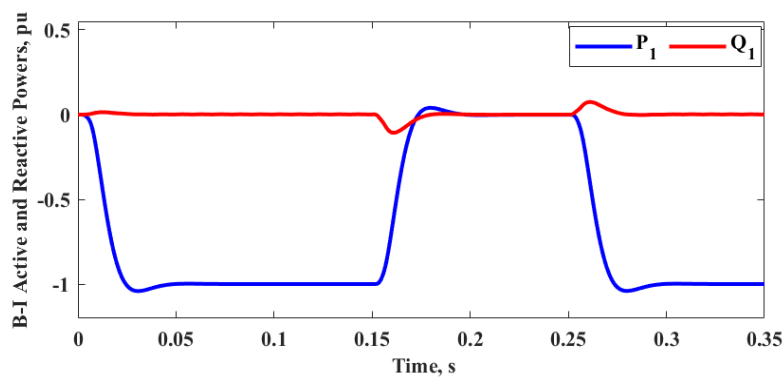

(a)

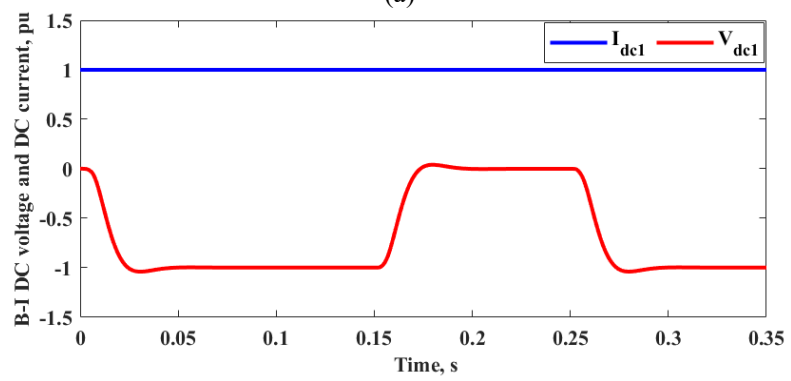

(c)

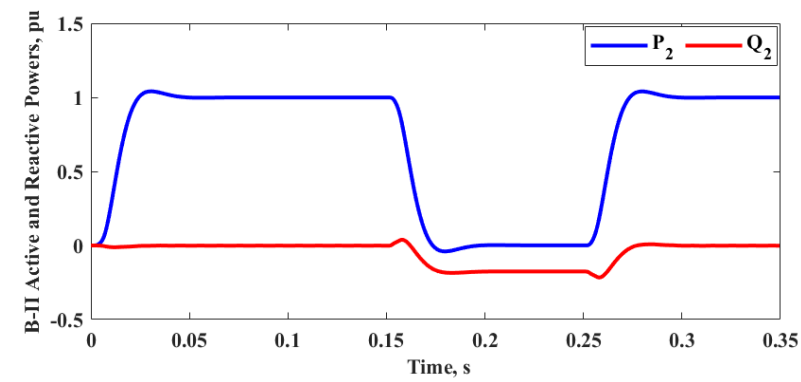

(b)

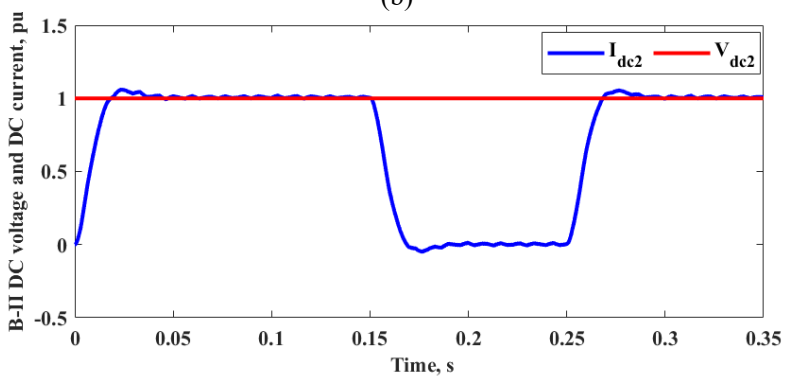

(d)

Fig. 15. Simulation results for dc pole to pole fault at B-I when receiving rated power from B-II. (a) Active and reactive powers at B-I (b) Active and reactive powers at B-II. (c) dc link voltage and current at B-I. (d) dc link voltage and current at $B-I I$.

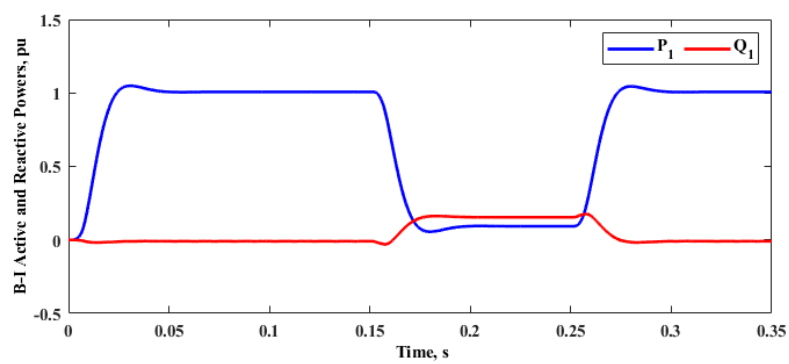

(a)

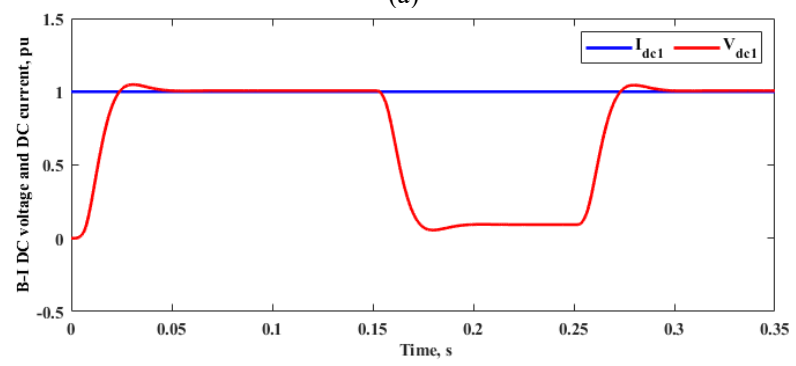

(c)

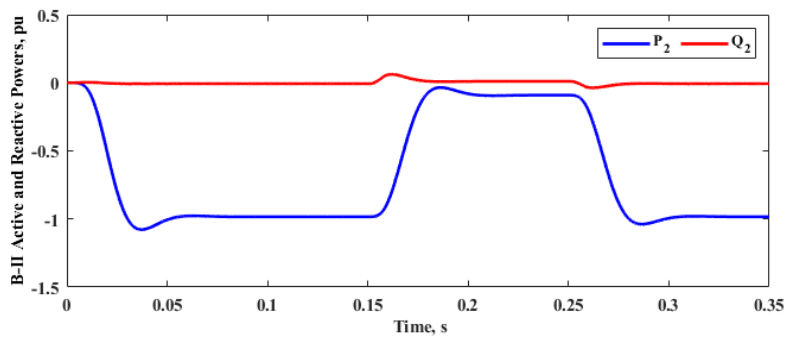

(b)

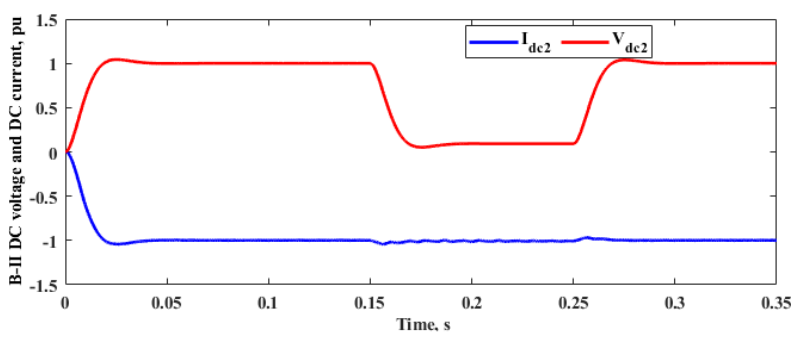

(d)

Fig. 16. Simulation results for dc pole to pole fault at B-II when receiving rated power from $B$-I. (a) Active and reactive powers at B-I (b) Active and reactive powers at B-II. (c) dc link voltage and current at B-I. (d) dc link voltage and current at $B-I I$.

\section{Proposed Converter Discussion and Topology Variations}

As illustrated in Fig. 2b, the proposed topology can be extended to three-phase in order to allow bulk power transfer. To simplify the analysis in this paper, rectangular ac waveforms are considered. Therefore, high $d i / d t$ and $d v / d t$ will be encountered at the LCC and the VSC sides, respectively. On the other hand, the capacitor at the LCC side and the inductor at the VSC side will result in nicer $d v / d t$ and $d i / d t$, respectively.
However, a trapezoidal waveform can be adopted for the ac current and the ac voltage generated across the inner $L C$ link. Such waveform will further reduce the $d v / d t$ generated across the transformer by utilising conventional Modular Multilevel Converter Sub-Modules (MMC-SMs), the Half-Bridge (HB) and the Full-Bridge (FB) types as in Fig. 17a. In trapezoidal modulation, the utilised MMC-SMs are inserted during the transition from positive to negative dc rails and vice-versa [11]. Additionally, applying the Transition Arm Converter (TAC) concept is viable, as illustrated in Fig. 17b. In TAC the lower 
MMC arms are replaced by series connected switches that operate under zero voltage switching [28].

B-II realisation with MMC-SMs is straightforward since BII is fed from a VSC, but incorporating MMC-SMs in B-I which is fed from LCC is not. Therefore, the SMs utilised in B-I and B-II are denoted $\mathrm{SM}_{i}$ and $\mathrm{SM}_{v}$, respectively, to distinguish between LCC and VSC based SMs. One of the possible suggestions, as in [29], is to incorporate the analogy concept; hence, an $\mathrm{SM}_{i}$ the inductor replaces the capacitor in the conventional $\mathrm{SM}_{v}$.

On the other hand, series connection of thyristors and IGCTs is well-established in the literature [30]. However, in the proposed converter there will be high $d i / d t$ which may lead to dynamic latch-up for the IGCTs. In practice, for series connected IGCTs it is necessary to add an RC snubber circuit to allow the IGCT to control the $d i / d t$ and $d v / d t$ during switching. Additionally, to avoid any destructive voltage imbalance among series connected switches, balancing circuit should be added in parallel to the IGCT, see Fig. 18 [31]. Generally, the $d i / d t$ of IGCTs has certain limit depending on the anode stray inductance $\left(\mathrm{L}_{\mathrm{IGCT}}\right)$. For higher $d i / d t$ rates, the anode inductance need to be increased to limit the $d i / d t$ to the device capability by adding a series inductor with the switch [25].

Finally, the ac link waveform frequency can be a factor to determine the converter transformer size. The higher the frequency the smaller the transformer size. Practically in high power and $\mathrm{HV}$ applications, the transformer size is restricted by its $\mathrm{HV}$ insulation and mechanical properties to support the weight of the HV bushes and to withstand the resultant magnetic forces. Therefore, the acceptable range for high frequency in high power and high voltage applications is up to $1 \mathrm{kHz}[17]$.

\section{Conclusion}

This paper proposed a new dc-dc converter topology concept to enable the possibility of connecting two HVDC systems with different topologies such as LCC and VSC. The proposed converter adopts self-commutated switches for interfacing both HVDC networks in addition to an $L C$ circuit. Where, IGCTs are utilised for LCC side and IGBTs are utilised for the VSC side. With proper control of the phase shift angle between the generated bridges ac link voltage and current, the power can be exchanged between both systems at zero reactive power at rated power. Unlike the hybrid HVDC connectivity solutions in the literature, the proposed converter provide simple control and reduced components. Additionally, the response of the proposed converter shows that, during de link pole-to-pole fault at the LCC or the VSC side, the fault is tolerable and the system can survive. As a result, the proposed converter can be a good candidate when applying HVDC integration between VSC and LCC based HVDC systems. On the down side, the proposed topology involve passive $L C$ elements, which are selected based on nullifying the bridges reactive powers at rated power transfer. Transferring the non-rated power will result in some reactive power exchange between bridges. Moreover, some reactive power will be evident during faults. The proposed converter conceptual analysis and operation modes are introduced. In addition to a proof-of-concept simulations and scaled-down experimentation.

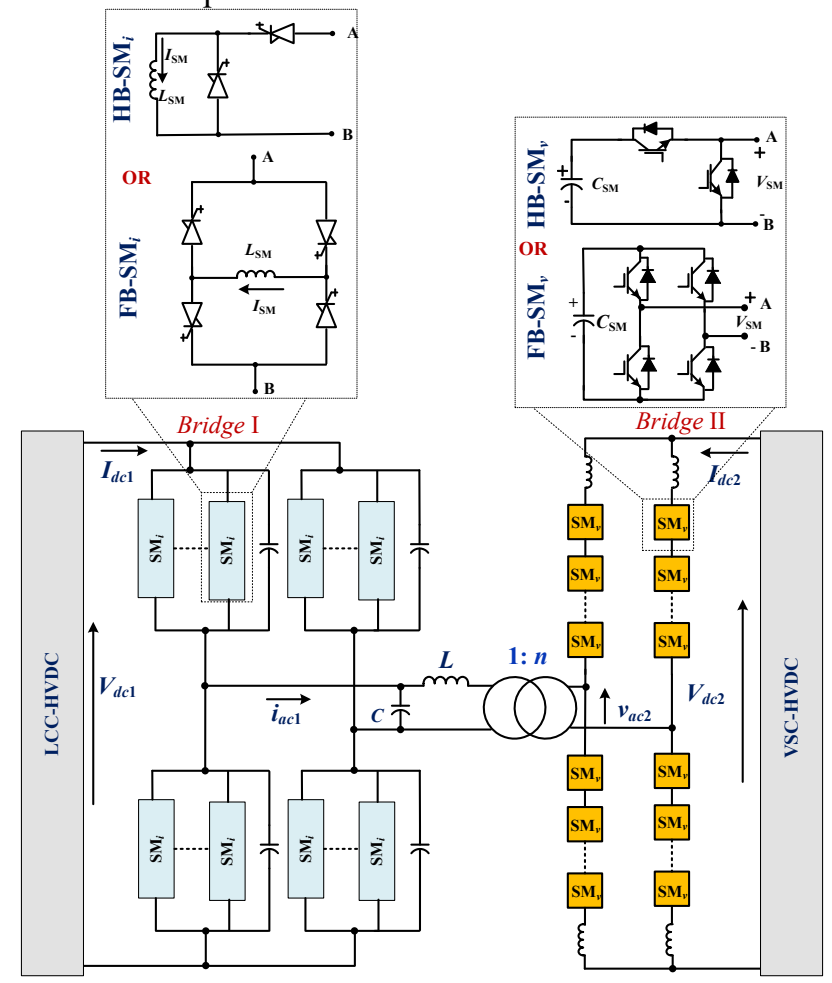

(a)

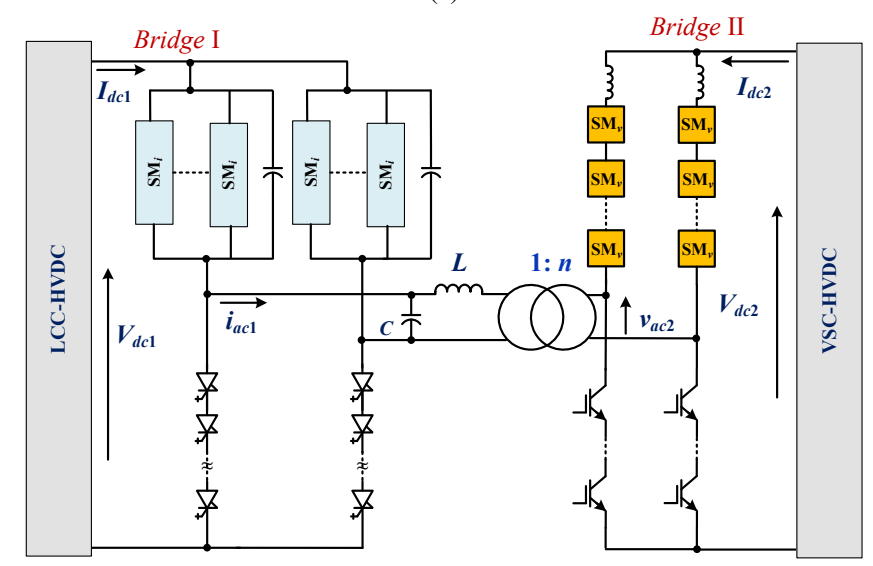

(b)

Fig. 17. Proposed converter topology variations for trapezoidal ac waveform. (a) With MMC-SMs. (b) With TAC concept.

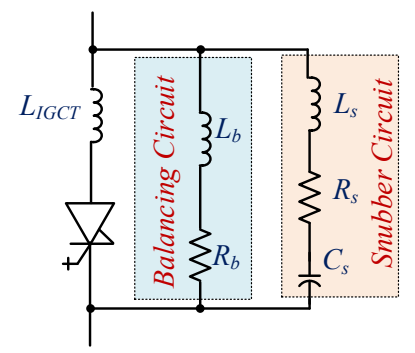

Fig. 18. IGCT snubber and balancing circuits. 


\section{References}

[1] N. Flourentzou, V. G. Agelidis, and G. D. Demetriades, "VSC-based HVDC power transmission systems: An overview," IEEE Trans. Power Electron., vol. 24, no. 3, pp. 592-602, 2009.

[2] A. Egea-Alvarez, F. Bianchi, A. Junyent-Ferre, G. Gross, and O. Gomis-Bellmunt, "Voltage control of multiterminal VSC-HVDC transmission systems for offshore wind power plants: Design and implementation in a scaled platform," IEEE Trans. Ind. Electron., vol. 60, no. 6, pp. 2381-2391, 2013.

[3] D. Van Hertem and M. Ghandhari, "Multi-terminal vsc hvde for the european supergrid: Obstacles," Renewable and Sustainable Energy Reviews, vol. 14, no. 9, pp. 3156-3163, 2010.

[4] A. Lesnicar and R. Marquardt, "An innovative modular multilevel converter topology suitable for a wide power range," in IEEE Bologna Power Tech Conference Proceedings, 2003.

[5] Barker et al., HVDC: Connecting to the Future. Paris, France: Alstom Grid, 2010.

[6] R. E. Torres-Olguin, M. Molinas, and T. Undeland, "Offshore wind farm grid integration by VSC technology with LCC-based HVDC transmission," IEEE Trans. Sustainable Energy, vol. 3, no. 4, pp. 899-907, 2012.

[7] D. Jovcic and J. Zhang, "High power IGBT-based de/dc converter with dc fault tolerance," in 15th International Power Electronics and Motion Control Conference (EPE/PEMC), 2012.

[8] R. W. A. A. D. Doncker, D. M. Divan, and M. H. Kheraluwala, "A three-phase soft-switched high-power-density dc/dc converter for high-power applications," IEEE Trans. Ind. Applicat., vol. 27, no. 1, pp. 63-73, 1991.

[9] A. A. Elserougi, A. Massoud, I. Abdelsalam, and S. Ahmed, "A selfbalanced bidirectional medium-/high-voltage hybrid modular dc-dc converter with low-voltage common dc-link and sequential charging/discharging of submodules capacitors," IEEE Trans. Ind. Electron., vol. 66, no. 4, pp. 2714-2725, 2019.

[10] X. Xiang, X. Zhang, T. Luth, M. M. C. Merlin, and T. C. Green, "A compact modular multilevel dc-dc converter for high step-ratio mv and HV use," IEEE Trans. Ind. Electron., vol. 65, no. 9, pp. 70607071, 2018.

[11] A. Gowaid, G. P. Adam, A. M. Massoud, S. Ahmed, D. Holliday, and B. W. Williams, "Quasi two-level operation of modular multilevel converter for use in a high-power dc transformer with dc fault isolation capability," IEEE Trans. Power Electron., vol. 30, no. 1, pp. 108-123, 2015

[12] B. Zhao, Q. Song, W. Liu, and Y. Sun, "Overview of dual-activebridge isolated bidirectional dc-dc converter for high-frequencylink power-conversion system," IEEE Trans. Power Electron., vol. 29, no. 8, pp. 4091-4106, 2014.

[13] G. P. Adam, K. H. Ahmed, S. J. Finney, K. Bell, and B. W. Williams, "New breed of network fault-tolerant voltage-source-converter HVDC transmission system," IEEE Trans. Power Syst., vol. 28, no. 1, pp. 335-346, 2013.

[14] K. H. Ahmed, G. P. Adam, I. A. Abdelsalam, and A. A. Aboushady, "Modular multilevel converter with modified half-bridge submodule and arm filter for dc transmission systems with dc fault blocking capability," IET Power Electronics, vol. 11, no. 14, pp. 2253-2262, 2018.

[15] D. Jovcic, "Bidirectional, high-power dc transformer," IEEE Trans. Power Delivery, vol. 24, no. 4, pp. 2276-2283, 2009.

[16] D. Jovcic and B. T. Ooi, "Developing de transmission networks using dc transformers," IEEE Trans. Power Delivery, vol. 25, no. 4, pp. 2535-2543, 2010.

[17] G. P. Adam, I. A. Gowaid, S. J. Finney, D. Holliday, and B. W. Williams, "Review of dc-dc converters for multi-terminal HVDC transmission networks," IET Power Electronics, vol. 9, no. 2, pp. 281-296, 2016.

[18] S. P. Engel, M. Stieneker, N. Soltau, S. Rabiee, H. Stagge, and R. W. D. Doncker, "Comparison of the modular multilevel dc converter and the dual-active bridge converter for power conversion in hvdc and mvdc grids," IEEE Trans. Power Electron., vol. 30, no. 1, pp. 124-137, 2015
[19] J. D. Páez, D. Frey, J. Maneiro, S. Bacha, and P. Dworakowski, "Overview of dc-dc converters dedicated to hvdc grids," IEEE Trans. Power Delivery, vol. 34, no. 1, pp. 119-128, 2019.

[20] R. E. Torres-Olguin, A. Garces, M. Molinas, and T. Undeland, "Integration of offshore wind farm using a hybrid hvde transmission composed by the pwm current-source converter and linecommutated converter," IEEE Trans. Energy Conversion, vol. 28, no. 1, pp. 125-134, 2013.

[21] M. Hajian, J. Robinson, D. Jovcic, and B. Wu, "30 kW, 200 V/900 V, Thyristor LCL DC/DC Converter Laboratory Prototype Design and Testing," IEEE Trans. Power Electron., vol. 29, no. 3, pp. 10941102, 2014.

[22] P. Li, G. P. Adam, S. J. Finney, and D. Holliday, "Operation Analysis of Thyristor-Based Front-to-Front Active-ForcedCommutated Bridge DC Transformer in LCC and VSC Hybrid HVDC Networks," IEEE Journal of Emerging and Selected Topics in Power Electronics, vol. 5, no. 4, pp. 1657-1669, 2017.

[23] Z. Yang, M. Li, X. Lu, W. Xiang, W. Zuo, L. Yao, et al., "Interconnection of VSC-HVDC and LCC-HVDC using DC-DC autotransformer," The Journal of Engineering, vol. 2019, no. 18, pp. 5033-5037, 2019.

[24] R. Zeng, B. Zhao, T. Wei, C. Xu, Z. Chen, J. Liu, et al., "Integrated gate commutated thyristor-based modular multilevel converters: A promising solution for high-voltage dc applications," IEEE Ind. Electron. Mag., vol. 13, no. 2, pp. 4-16, 2019.

[25] B. Zhao, R. Zeng, Z. Yu, Q. Song, Y. Huang, Z. Chen, et al., "A more prospective look at igct: Uncovering a promising choice for $\mathrm{dc}$ grids," IEEE Ind. Electron. Mag., vol. 12, no. 3, pp. 6-18, 2018.

[26] M. A. Elgenedy, A. A. Elserougi, A. S. Abdel-Khalik, A. M. Massoud, and S. Ahmed, "A Space Vector PWM Scheme for FivePhase Current-Source Converters," IEEE Trans. Ind. Electron., vol. 63 , no. 1, pp. 562-573, 2016.

[27] M. A. Elgenedy, A. S. Abdel-Khalik, A. A. Elserougi, S. Ahmed and A. Massoud, "A Current-Source-Converter-Based PMSG Wind Energy Conversion System: Simulation Study," $15^{\text {th }}$ International Middle East Power System Conference (MEPCON), 2012.

[28] I. A. Gowaid, G. P. Adam, B. W. Williams, A. M. Massoud, S. Ahmed, "The transition arm multilevel converter - A concept for medium and high voltage DC-DC transformers," International Conference on Industrial Technology (ICIT), 2015.

[29] A. Nami, J. Liang, F. Dijkhuizen, and G. D. Demetriades, "Modular Multilevel Converters for HVDC Applications: Review on Converter Cells and Functionalities," IEEE Trans. Power Electron., vol. 30, no. 1, pp. 18-36, 2015.

[30] B. Wu, High Power Converter Systems. Piscataway, NJ, USA: IEEE Press, 2006

[31] Z. Zhao, L. Yuan, H. Bai, and T. Lu, Electromagnetic Transients of Power Electronics Systems: Springer, 2019. 